\title{
MEMBRANE POTENTIAL IN REVERSE OSMOSIS PROCESS
}

\author{
NAOCHIKa KANEKO* AND YUTAKa YAMAMOTO \\ Department of Nuclear Engineering, University of Tokyo, \\ Tokyo, 113
}

It is well known that an electric double layer appears in the boundary phase of solid and solution when a macromolecular solid contacts an electrolyte solution, and the potential thus generated is called phase boundary potential or zeta potential. Reverse osmosis, which has received great attention as a method of desalting sea water ${ }^{2}$, is a process of filtrating various electrolytes through membranes by a pressure gradient to produce pure water. Until now the cellulose acetate membrane has been one of the most successful for this purpose. The macromolecular segments such as cellulose acetate have a phase boundary potential on contact with electrolytes which affects the desalting ability of the membrane in the reverse osmosis process. Little work has been done in this field, and in our studies we attempted to measure the streaming potential of the membrane and throw light on the desalting mechanism of membranes.

\section{Experimental}

A flow sheet of the experimental apparatus and a schematic cell used in the study are shown in Figs. 1 and 2. The membranes were regenerated cellulose (cellophane denoted RC) and Loeb-type cellulose acetate membrane, respectively. The latter was treated in hot water at $80^{\circ} \mathrm{C}$ (film-type CA-80) and at $70^{\circ} \mathrm{C}$ (film-type CA-70) respectively, while the filmtype CA-00 was not treated. The potential was measured by using two gold electrodes which were placed above and below the membrane (see Fig. 2). An example of a streaming potential curve is illustrated in Fig. 3. The potential decreases rapidly with time because of increasing concentration polarization which takes place with the accumulation of concentrated salt on the surface of the membrane. For this reason, the first peak in Fig. 3 was taken as the streaming potential at the initial feed concentration. Further, rejection coefficients in the reverse osmosis process were obtained by using a cell which has a magnetic stirrer on the surface of the membrane to prevent concentration polarization. The rejection coefficient $f$ is defined as follows:

$$
f=\frac{\text { product concentration }}{\text { feed concentration }}
$$

Received November 11, 1975.

\section{Results and Discussion}

The relation of streaming potential $H$ and zetapotential $\zeta$ or charge density $\sigma$ at operating pressure $P$ is generally expressed as follows:

$$
H=\frac{P \varepsilon \zeta}{4 \pi \eta K^{*}}=\frac{P \sigma}{\eta \kappa K^{*}}
$$

where $K^{*}$ is the specific conductivity of solute in the membrane. As it is difficult to measure this value $K^{*}$ the following relation between specific conductivity of the feed $K$ and the rejection coefficient $f$ by reverse osmosis was assumed in order to calculate zeta potential:

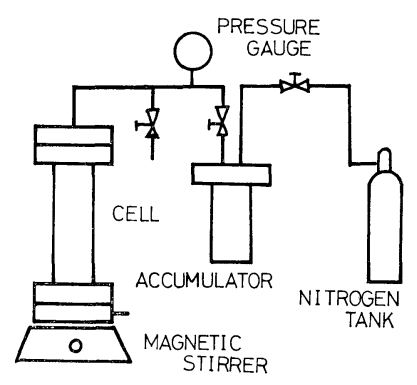

Fig. 1 Schematic diagram of experimental apparatus and reverse osmosis process

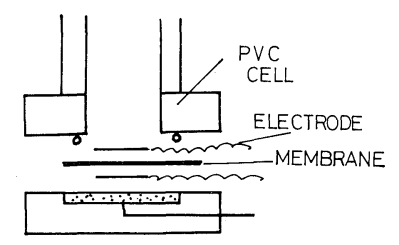

Fig. 2 Schematic diagram of streaming potential cell

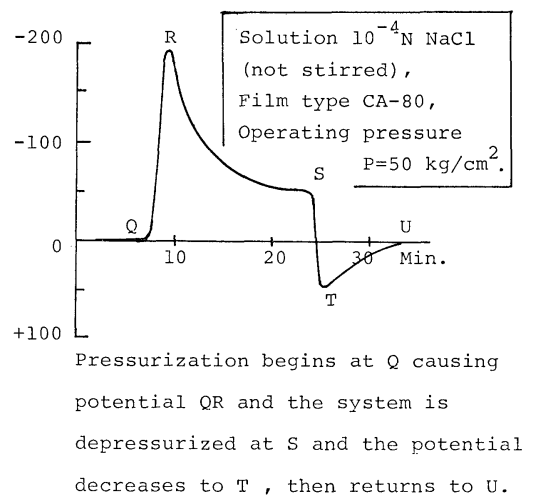

Fig. 3 An example of streaming potential curve 
Table 1 Zeta potential by various electrolytes

\begin{tabular}{|c|c|c|c|c|c|}
\hline Solute & $10^{-5}$ & $10^{-4}$ & $\begin{array}{c}\text { concentration } \\
10^{-3}\end{array}$ & $10^{-2}$ & $10^{-1}$ \\
\hline $\mathrm{KCl}$ & $-1.8 \times 10^{-3}$ & $-4.6 \times 10^{-3}$ & $-3.0 \times 10^{-3}$ & $-1.4 \times 10^{-2}$ & $+4.4 \times 10^{-1}$ \\
\hline $\mathrm{NaCl}$ & $-3.3 \times 10^{-3}$ & $-6.6 \times 10^{-3}$ & $-4.2 \times 10^{-2}$ & $-5.7 \times 10^{-2}$ & $+4.7 \times 10^{-1}$ \\
\hline $\mathrm{MgCl}_{2}$ & $-4.1 \times 10^{-3}$ & $-6.9 \times 10^{-3}$ & $-1.4 \times 10^{-2}$ & $-9.2 \times 10^{-3}$ & $+6.5 \times 10^{-2}$ \\
\hline $\mathrm{Na}_{2} \mathrm{SO}_{4}$ & $-1.5 \times 10^{-3}$ & $-5.1 \times 10^{-3}$ & $-9.2 \times 10^{-3}$ & $-9.1 \times 10^{-3}$ & $-3.2 \times 10^{-2}$ \\
\hline $\mathrm{MgSO}_{4}$ & $-2.2 \times 10^{-3}$ & $-3.6 \times 10^{-3}$ & $-4.8 \times 10^{-3}$ & $-6.7 \times 10^{-3}$ & $1.2 \times 10^{-2}$ \\
\hline
\end{tabular}

operating pressure $P=50 \mathrm{~kg} / \mathrm{cm}^{2}$, film type CA-80

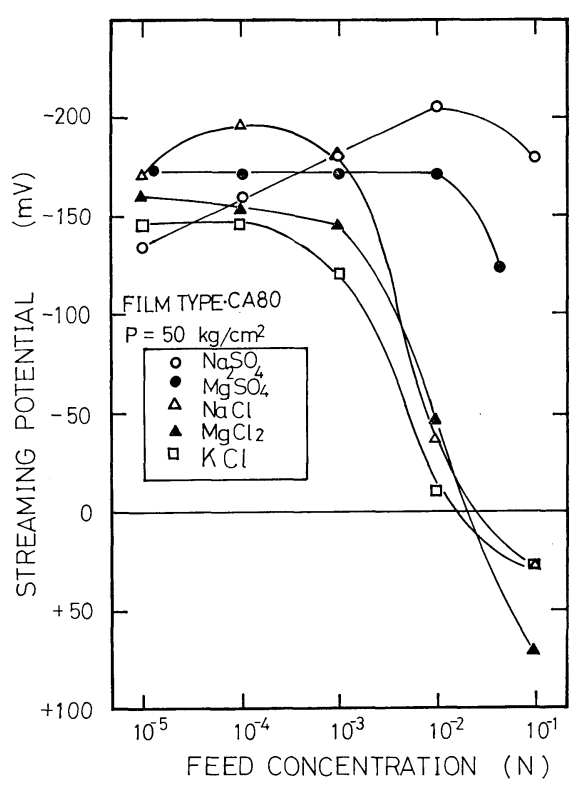

Fig. 4 Effect of feed concentration on streaming potential for various electrolytes

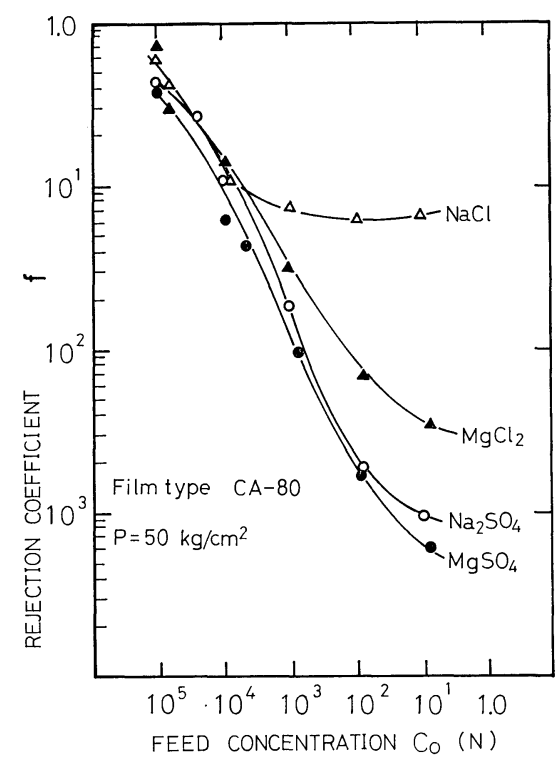

Fig. 5 Effect of feed concentration on rejection coefficients in reverse osmosis

$$
K^{*}=K \times f
$$

The results are shown in Tables 1 and 2 and Figs. 4, 5 and 6. From these results the following interesting
Table 2 Zeta-potential of various membranes by $\mathrm{KCl}$ solution

Feed concentration $\mathrm{C}_{0}(\mathrm{~N})$

\begin{tabular}{lcccc}
$\begin{array}{l}\text { Mem- } \\
\text { brane }\end{array}$ & $10^{-4}$ & $10^{-3}$ & $10^{-2}$ & $10^{-1}$ \\
\hline CA-00 & $-7.9 \times 10^{-2}$ & $-5.0 \times 10^{-1}$ & $-6.5 \times 10^{-1}+1.16$ \\
CA-70 & $-1.9 \times 10^{-2}$ & $-1.2 \times 10^{-1}$ & $-2.0 \times 10^{-1}+1.20$ \\
CA-80 & $-4.6 \times 10^{-3}$ & $-3.0 \times 10^{-3}$ & $-1.4 \times 10^{-2}$ & $+4.4 \times 10^{-1}$ \\
RC & $-3.9 \times 10^{-3}$ & $-3.9 \times 10^{-2}$ & $-2.5 \times 10^{-1}$ & $-4.3 \times 10^{-1}$
\end{tabular}

operating pressure $P=50 \mathrm{~kg} / \mathrm{cm}^{2}$

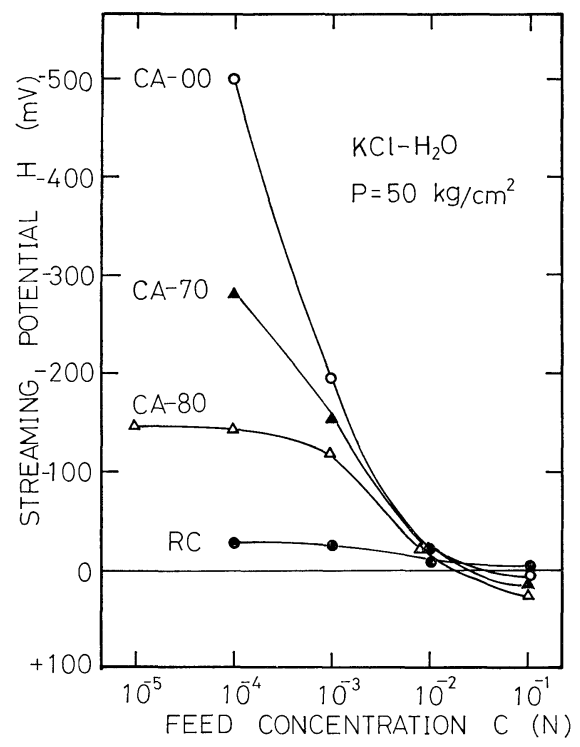

Fig. 6 Streaming potential of various cellulose acetate membranes and of regenerated cellulose ( $\mathrm{RC}$ is cellophane) for $\mathrm{KCl}$

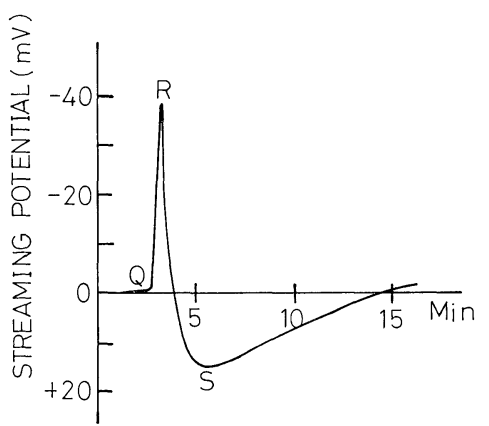

Fig. 7 Streaming potential curve with time for CA-80 memb. in $0.01 \mathrm{~N} \mathrm{NaCl}$ 
facts were observed: 1) CA-membranes have an iso-electric point at around feed concentration $0.02 \mathrm{~N}$ for $\mathrm{KCl}, \mathrm{NaCl}$ and $\mathrm{MgCl}_{2}$ solution, while there is no such point for $\mathrm{Na}_{2} \mathrm{SO}_{4}$ and $\mathrm{MgSO}_{4}$ in the range studied. An interesting example of a streaming potential curve with time for $0.01 \mathrm{~N} \mathrm{NaCl}$ is illustrated in Fig. 7. The figure shows that the change in potential direction is from negative to positive with time. The region of this feed concentration is threshold where the potential reverses, then the rapid accumulation of solutes on the surface by reverse osmosis process might change the potential from negative to positive. 2) Membranes treated at a lower temperature have a greater zeta potential than those treated at a higher temperature. 3) Absolute zeta potential values of membranes seem to increase with feed concentration except around the iso-electric point. 4) Rejection rate (i.e. $(1-f) \times 100 \%$ ) increases with increasing feed concentration in a certain range as shown in Fig. 5. These phenomena may be caused by interaction of ions in the solution with dipolar groups such as $-\mathrm{OCOCH}_{3}$ and $-\mathrm{OH}$ in cellulose acetate segments and also by the configuration change of such dipolar groups in the formation of the membrane and in micro-Brownian movement by heat treatment. The cellulose acetate containing such dipolar groups adsorbs both positive and negative ions and it seems rather to have the character of a double charged membrane $^{1}$, while it appears to be a neutral membrane as a whole.

$$
\begin{array}{llr}
\text { Nomenclature } & \\
f & =\text { rejection coefficient } & {[-]} \\
H & =\text { streaming potential } & {[\mathrm{mV}]} \\
K & =\text { specific conductivity of solution } & {\left[\Omega^{-1} \mathrm{~cm}^{-1}\right]} \\
K^{*} & =\text { specific conductivity in the membrane } & {\left[\Omega^{1-} \mathrm{cm}^{-1}\right]} \\
P & =\text { pressure } & {\left[\mathrm{kg} / \mathrm{cm}^{2}\right]} \\
\varepsilon & =\text { dielectric constant of water } & {[-]} \\
\eta & =\text { viscosity coefficient } & {[\mathrm{poise}]} \\
1 / \kappa & =\text { average thickness of ionic atmosphere } & {[\mathrm{cm}]} \\
\sigma & =\text { charge density of membrane } & {\left[\mathrm{csu} / \mathrm{cm}^{2}\right]} \\
\zeta & =\text { zeta potential of membrane } & {[\mathrm{mV}]}
\end{array}
$$

\section{Literature Cited}

1) Lakshminarayanaiah, N.: "Transport Phenomena in Membrane" pp. 293-297, Academic Press (1969).

2) Sourirajan, S.: "Reverse Osmosis", Logos Press Limited (1970). 